\title{
Role of MSCT in the diagnosis of perforated gall bladder (a retrospective study)
}

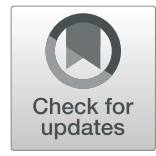

Mohamed M. Harraz (i) and Ahmed H. Abouissa

\begin{abstract}
Background: Although gall bladder perforation (GBP) is not common, it is considered a life-threating condition, and the possibility of occurrence in cases of acute cholecystitis must be considered. The aim of this study was to assess the role of multi-slice computed tomography (MSCT) in the assessment of GBP.

Results: It is a retrospective study including 19 patients that had GBP out of 147, there were 11 females (57.8\%) and 8 males (42.1\%), aged 42 to 79 year (mean age 60) presented with acute abdomen or acute cholecystitis. All patients were examined with abdominal ultrasonography and contrast-enhanced abdominal MSCT after written informed consent was obtained from the patients. This study was between January and December 2018. Patients with contraindications to contrast-enhanced computed tomography (CT) (pregnancy, acute kidney failure, or allergy to iodinated contrast agents) who underwent US only were excluded. Patients with other diagnoses, such as acute diverticulitis of the right-sided colon or acute appendicitis, were excluded. The radiological findings were evaluated such as GB distention; stones; wall thickening, enhancement, and defect; pericholecystic free fluid or collection; enhancement of liver parenchyma; and air in the wall or lumen. All CT findings are compared with the surgical results. Our results revealed that the most important and diagnostic MSCT finding in GBP is a mural defect.

Nineteen patients were proved surgically to have GBP.

Conclusion: GBP is a rare but very serious condition and should be diagnosed and treated as soon as possible to decrease morbidity and mortality. The most accurate diagnostic tool is the CT, MSCT findings most specific and sensitive for the detection of GBP and its complications.
\end{abstract}

Keywords: MDCT, GB, Perforation, Ultrasonography

\section{Background}

Although gall bladder perforation (GBP) is not common, due to its high mortality rate, the possibility of occurrence in cases of acute cholecystitis must be considered. Clinically, it resembles the uncomplicated acute cholecystitis and this explains the delayed diagnosis; many cases are diagnosed only during surgery. Therefore, proper radiological evaluation is crucial [1].

GBP usually starts with the impaction of a bile stone in the cystic duct, followed by gallbladder distension, vascular impairment, and ischemia of the gallbladder wall, usually at the fundus, which is the most distal part and therefore poorly vascularized. The ischemic part necrotizes and eventually ruptures, sometimes precipitated by infection. Perforation may also follow acalculous

\footnotetext{
* Correspondence: harrazharraz@live.com

Radiology Department, Mansoura University Hospitals, Mansoura, Egypt
}

cholecystitis, although rarely. Certain gallbladder diseases, such as emphysematous and gangrenous cholecystitis, malignancy and trauma, are especially associated with high risk [2].

According to the revised Niemeier's classification, there are three types of GBP: type I-acute, free GBP and generalized biliary peritonitis-rarest, but with the worst prognosis; type II-subacute, pericholecystic collection and localized peritonitis-most common; and type III-chronic, internal fistula-mostly to the duodenum or common bile duct. Symptoms of type I and type II very much resemble acute uncomplicated cholecystitis. Type III may cause gastrointestinal obstruction (gallstone ileus). While type I and II are usually accompanied by fever and elevated WBC count, type III rarely causes fever and shows only a slight increase in WBC count [2]. In some cases, a sudden decrease in pain due to decompression may be a sign of perforation. GBP should be 
Table 1 The most common associated systemic disease with GBP

\begin{tabular}{lll}
\hline & Number of cases & Cases (\%) \\
\hline Diabetes mellitus & 11 & $57.8 \%$ \\
Hypertension & 10 & $52.6 \%$ \\
Cerebrovascular disorders & 9 & $47.3 \%$ \\
Others & 7 & $36.8 \%$ \\
\hline
\end{tabular}

considered with acute cholecystitis when the clinical condition deteriorates rapidly [3].

Type I perforation is often associated with atherosclerosis, diabetes, malignancy, cirrhosis, and immunosuppression, without a history of chronic cholecystitis, while type III perforation usually occurs in patients with a long-time history of gallstones [2].

Ultrasound is usually the initial imaging method in radiological evaluation of GBP and it yields excellent results. However, intestinal gas and pain may limit its accuracy. Computed tomography (CT) is the most sensitive imaging method for GBP and often follows ultrasound examinations [4]. The aim of this study was to assess the role of multi-slice computed tomography (MSCT) in the assessment of GBP.

\section{Methods}

It is a retrospective study including 19 patients that had GBP out of 147 , there were 11 females (57.8\%) and 8 males $(42.1 \%)$, aged 42 to 79 year (mean age 60) presented with acute abdomen or acute cholecystitis. All patients were examined with abdominal ultrasonography and contrast-enhanced abdominal MSCT after written informed consent was obtained from patients. This study was between January and December 2018. Patients with contraindications to contrast-enhanced CT (pregnancy, acute kidney failure, or allergy to iodinated contrast agents) who underwent US only were excluded. Patients with other diagnoses, such as acute diverticulitis of the right-sided colon or acute appendicitis, were excluded.

\section{US technique}

\section{Ultrasound assessment}

The ultrasound examination was performed with the GE Logiq E9 Medical System, using a convex transducer of 3.5 MHz. No special preparation of the patients was necessary. Patients were studied in supine and left lateral decubitus position. The scans were reviewed and the US radiological

Table 2 Gall bladder perforation classification from total of 19 examined patients

\begin{tabular}{lllllll}
\hline \multicolumn{2}{l}{ Gall bladder perforation type I } & & Gall bladder perforation type \\
\cline { 1 - 4 } Operative & CT & US & Operative & CT & US \\
\hline 5 & 5 & 1 & 14 & 14 & 5 \\
\hline
\end{tabular}

Table 3 Imaging findings including US and CT

\begin{tabular}{|c|c|c|c|c|}
\hline \multirow[t]{2}{*}{ Imaging findings } & \multicolumn{2}{|l|}{ US } & \multicolumn{2}{|l|}{$C T$} \\
\hline & $\begin{array}{l}\text { Type I } \\
\text { GBP }\end{array}$ & $\begin{array}{l}\text { Type } \| \\
\text { GBP }\end{array}$ & $\begin{array}{l}\text { Type I } \\
\text { GBP }\end{array}$ & $\begin{array}{l}\text { Type II } \\
\text { GBP }\end{array}$ \\
\hline GB stones & 4 & 11 & 4 & 10 \\
\hline Thick-walled GB & 5 & 11 & 5 & 11 \\
\hline Distended GB & 5 & 11 & 5 & 11 \\
\hline Pericholecystic free fluid & 3 & 13 & 3 & 13 \\
\hline Pericholecystic abscess & 3 & 13 & 3 & 14 \\
\hline Free intra-peritoneal fluid & 5 & 14 & 5 & 14 \\
\hline Wall defect & - & 2 & 5 & 14 \\
\hline Fundus & - & 2 & 2 & 7 \\
\hline Other sites & - & - & 3 & 7 \\
\hline Single defect & - & 2 & 4 & 12 \\
\hline Multiple defects & - & - & 1 & 2 \\
\hline $\begin{array}{l}\text { Inflammatory changes in } \\
\text { hepatic flexure of colon }\end{array}$ & - & - & 2 & 8 \\
\hline $\begin{array}{l}\text { Pericholecystic hepatic } \\
\text { enhancement }\end{array}$ & - & - & 3 & 6 \\
\hline
\end{tabular}

findings were evaluated involving GB distension (largest diameter $>3.5-4.0 \mathrm{~cm}$ ), wall defect, wall thickening (thicker than $3 \mathrm{~mm}$ ), pericholecystic free fluid or collection, gall bladder (GB) stones, and free intra-peritoneal fluid.

\section{CT technique}

Non-enhanced and portal venous phase series were acquired using a 128-section CT scanner (Siemens Somatom Definition AS). The protocol was $5 \mathrm{~mm}$ slice thickness for the pre-contrast scan and $2.5 \mathrm{~mm}$ slice thickness for postcontrast scans, $120 \mathrm{kV}, 365 \mathrm{mAs}$, and rotation time $0.5 \mathrm{~s}$. One milliliter per kilogram of IV iodinated contrast was injected at $3-4 \mathrm{ml} / \mathrm{s}$ over a period of $30-40 \mathrm{~s}$. The scan started 50-60 s after contrast injection (depending on the patient's heart condition). If the oral contrast indicated 750 $\mathrm{ml}$ of water-soluble iodinated contrast diluted to $1 \%$ used as oral contrast. The CT scans were reviewed and the radiological findings were evaluated such as GB distention, stones, wall thickening, wall enhancement, wall defect,

Table 4 Chi-squared independence test (non-parametric test) for the measurement of expectation between CT and US imaging type I GBP

\begin{tabular}{lll}
\hline Test statistics & $\begin{array}{c}\text { CT imaging findings } \\
\text { type IGBP }\end{array}$ & $\begin{array}{l}\text { US imaging findings } \\
\text { type IGBP }\end{array}$ \\
\hline Chi-squared & $6.133^{\mathrm{a}}$ & $1.692^{\mathrm{b}}$ \\
$\mathrm{df}$ & 12 & 5 \\
Asymp. Sig. & 0.909 & 0.890 \\
\hline a 13 cells (100.0\%) have expected frequencies less than 5. The minimum \\
$\begin{array}{l}\text { expected cell frequency is } 3.5 \\
\text { b } 6 \text { cells (100.0\%) have expected frequencies less than } \\
\text { expected cell frequency is } 4.3\end{array}$
\end{tabular}


pericholecystic inflammation, fluid, abscess, enhancement of liver parenchyma, and air in the wall or lumen, biliary radicals, pancreas, and intestinal loops. All CT findings are compared with US and surgical results.

\section{Statistical analysis}

Descriptive statistics, measurement of the agreement by kappa value and $p$ value, were obtained for patients' age, sex, current presentation, medical history, clinical information, and imaging finding including CT and US compared with operative findings in all cases.

\section{Results}

Nineteen patients were proved perforated GB. Their ages ranged from 42 to 79 years (mean age of 60 years). There were 11 females $(57.8 \%)$ and 8 males (42.1\%). Surgical confirmation of GBP was obtained for all patients. The most common presenting symptom was acute upper abdominal pain in 16 cases (84.2\%) and other symptoms such as fever, nausea, and vomiting. The most common associated disease was diabetes in 11 patients (57.8\%) (Table 1$)$. Fourteen patients $(73.6 \%)$ had type 2 perforation (subacute, localized), and only five had type 1 (acute, generalized peritonitis) perforation and no
Table 5 Chi-squared independence test (non-parametric test) for the measurement of expectation between CT and US imaging type II GBP

\begin{tabular}{lll}
\hline Test statistics & & \\
\hline & $\begin{array}{l}\text { CT imaging findings } \\
\text { type IIGBP }\end{array}$ & $\begin{array}{l}\text { US imaging findings } \\
\text { type IIGBP }\end{array}$ \\
\hline Chi-squared & $16.620^{\mathrm{a}}$ & $24.557^{\mathrm{b}}$ \\
df & 12 & 8 \\
Asymp. Sig. & 0.164 & 0.002
\end{tabular}

a 0 cells $(0.0 \%)$ have expected frequencies less than 5 . The minimum expected cell frequency is 9.9

${ }^{\mathrm{b}} 0$ cells $(0.0 \%)$ have expected frequencies less than 5 . The minimum expected cell frequency is 8.8

patient had type 3 perforation (Table 2). From Table 3, we found 15 patients had biliary calculi, and all were in the gallbladder. GB stone in one patient was missed on CT because of its low attenuation value, which rendered it iso-dense with gallbladder contents so ultrasonography is better in the assessment of stones. Regarding CT findings, the most important point was the detection of wall defect, either single or multiple and its site: fundus, body, or neck. In the 19 patients in whom a perforation was identified at CT, $16(84.2 \%)$ were solitary. Multiple perforations were identified in only three cases (15.7\%).

Table 6 Measurement of the agreement by kappa value and comparison between the observed CT accuracy and the expected accuracy done by operation approach

\begin{tabular}{|c|c|c|c|c|c|}
\hline & & & \multicolumn{2}{|c|}{$\begin{array}{l}\text { CT gall bladder perforation } \\
\text { classification }\end{array}$} & \multirow[t]{2}{*}{ Total } \\
\hline & & & $\begin{array}{l}\text { CT-classified } \\
\text { type I }\end{array}$ & $\begin{array}{l}\text { CT-classified } \\
\text { type II }\end{array}$ & \\
\hline \multirow{6}{*}{$\begin{array}{l}\text { Gall bladder perforation classification } \\
\text { made based on operative findings }\end{array}$} & \multirow{3}{*}{$\begin{array}{l}\text { Operation-classified } \\
\text { type I }\end{array}$} & Count & 5 & 0 & 5 \\
\hline & & $\begin{array}{l}\% \text { within gall bladder perforation } \\
\text { classification made based on operative } \\
\text { findings }\end{array}$ & $100.0 \%$ & $0.0 \%$ & $100.0 \%$ \\
\hline & & $\begin{array}{l}\% \text { within CT gall bladder perforation } \\
\text { classification }\end{array}$ & $100.0 \%$ & $0.0 \%$ & $26.3 \%$ \\
\hline & \multirow{6}{*}{$\begin{array}{l}\text { Operation-classified } \\
\text { type II }\end{array}$} & Count & 0 & 14 & 14 \\
\hline & & $\begin{array}{l}\% \text { within gall bladder perforation } \\
\text { classification made based on operative } \\
\text { findings }\end{array}$ & $0.0 \%$ & $100.0 \%$ & $100.0 \%$ \\
\hline & & $\begin{array}{l}\% \text { within CT gall bladder perforation } \\
\text { classification }\end{array}$ & $0.0 \%$ & $100.0 \%$ & $73.7 \%$ \\
\hline \multirow[t]{3}{*}{ Total } & & Count & 5 & 14 & 19 \\
\hline & & $\begin{array}{l}\% \text { within gall bladder perforation } \\
\text { classification made based on operative } \\
\text { findings }\end{array}$ & $26.3 \%$ & $73.7 \%$ & $100.0 \%$ \\
\hline & & $\begin{array}{l}\% \text { within CT gall bladder perforation } \\
\text { classification }\end{array}$ & $100.0 \%$ & $100.0 \%$ & $100.0 \%$ \\
\hline \multicolumn{6}{|l|}{ Symmetric measures } \\
\hline & & Value & Asymp. Std. Error ${ }^{a}$ & Approx. $T^{\mathrm{b}}$ & Approx. Sig. \\
\hline Measure of Agreement & Kappa & 1.000 & 0.000 & 4.359 & 0.001 \\
\hline$N$ of valid cases & & 19 & & & \\
\hline
\end{tabular}

${ }^{a}$ Not assuming the null hypothesis

busing the asymptotic standard error assuming the null hypothesis 
Table 7 Measurement of the agreement by kappa value and comparison between the observed US accuracy and the expected accuracy done by operation approach

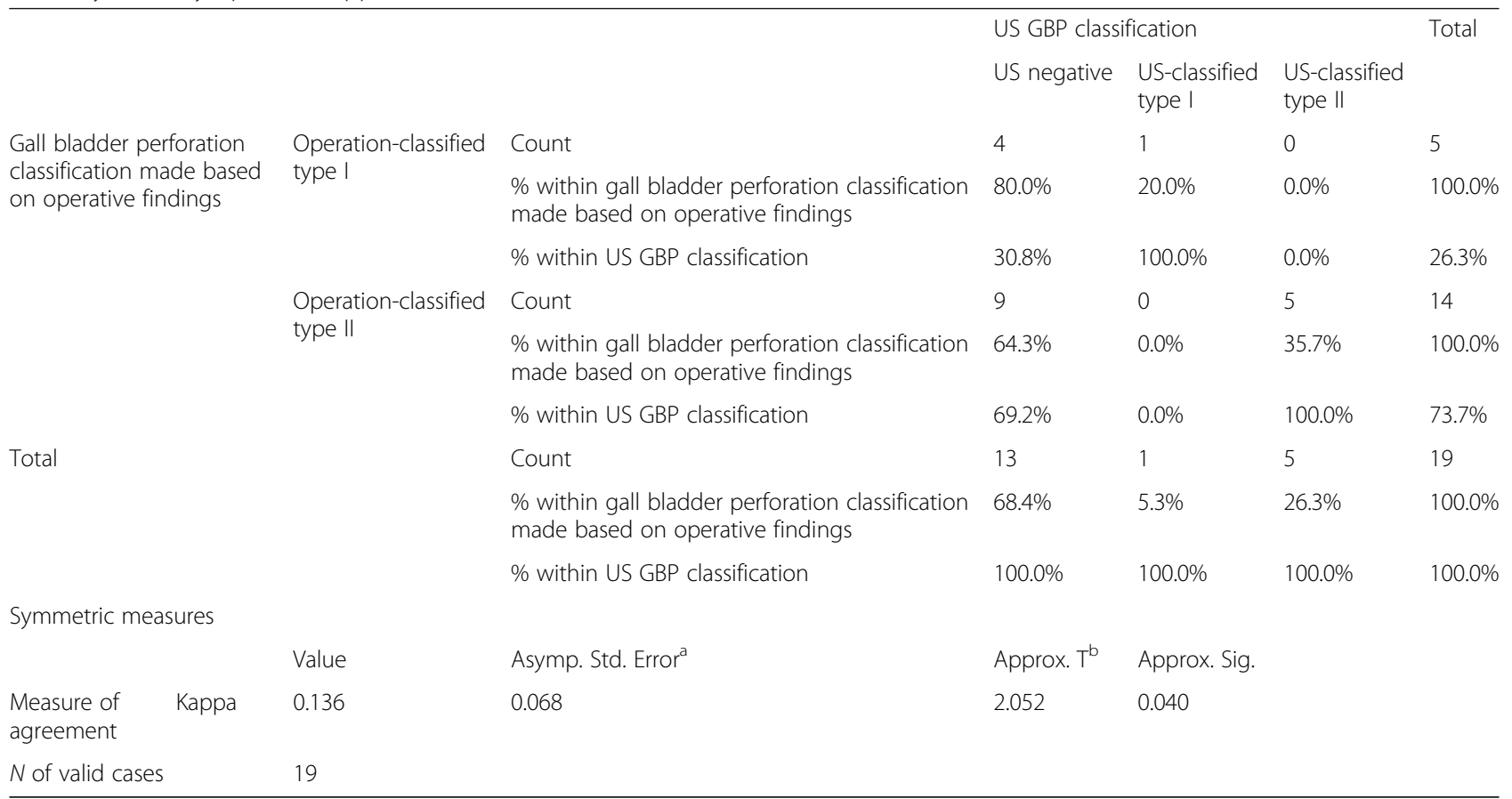

${ }^{a}$ Not assuming the null hypothesis

${ }^{b}$ Using the asymptotic standard error assuming the null hypothesis

The fundus was found to be the most common site of perforation in nine cases (48\%). GB wall enhancement is noted with cholecystitis however no enhancement with gangrenous GB. GB wall defect communicates with a collection is a hallmark for diagnosis. Site of an associated collection can occur anywhere but the most common sites are perihepatic, lesser sac, and liver bed, and in our study, we found 17 cases with one missing in the US. In this study, we detected by CT inflammatory changes in hepatic flexure of the colon (10 cases) and pericholecystic enhancement (9 cases). Other findings such as thick wall GB (16 cases), GB distension (16 cases), pericholecystic free fluid (16 cases), and intraperitoneal free fluid (19 cases) could be diagnosed by US and CT equally. In our study, we see that USG could diagnose 6 out of 19 cases as GBP, one case type I, and 5 cases type II. While CT had no negative results compared to USG (13 out of $19=68.4 \%$ ). CT could correctly diagnose all cases of types I and II GBP. From Tables 4 and 5 , we found that in type I, $p$ value was 0.9 , i.e., there is no significant difference between examination using CT and US in the detection of a radiological finding;

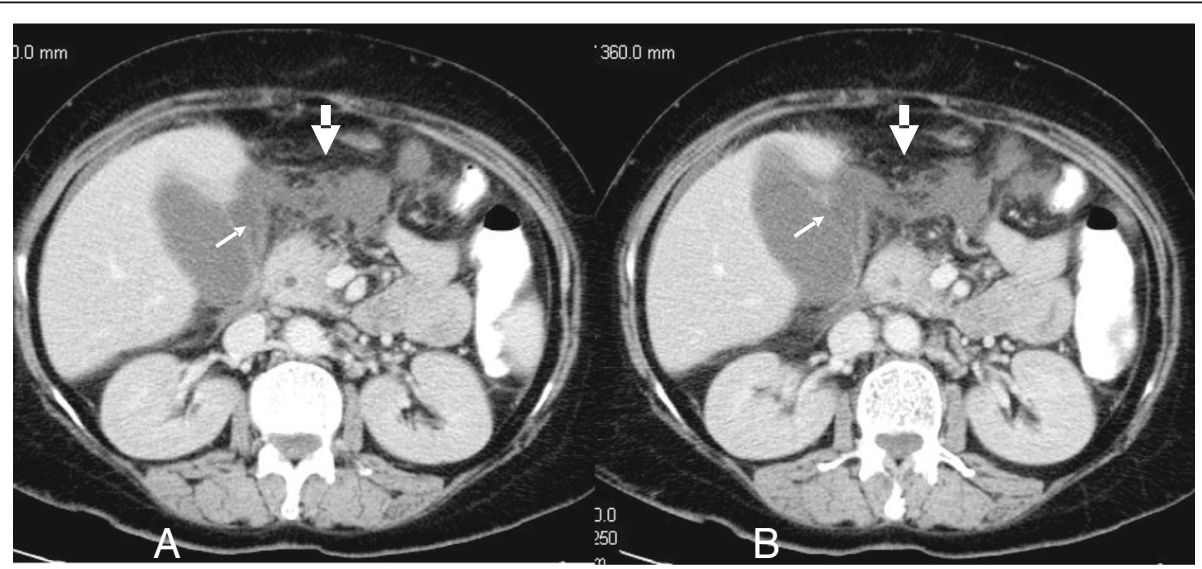

Fig. 1 a, b A 70-year-old female with DM and acute abdomen. Focal defect is seen in GB wall (thin arrows) communicating with a collection in the lesser sac (large arrows). No stones. Surgery revealed acute non-calcular cholecystitis with GB rupture 
however, in type II GBP, $p$ value was 0.002 , i.e., there is significant difference between examination using $\mathrm{CT}$ and US in the detection of a radiological finding in the diagnosis of GBP and this agrees with. Finally, we have assessed the percentage agreement of preoperative findings of USG and $\mathrm{CT}$ with actual perioperative findings, respectively. Thus from these tables (Tables 6 and 7), we can see that there was a higher percentage of agreement between CT and operative findings (kappa score 1 and $p$ value less than 0.001 ) with highest sensitivity and specificity of CT examination technique in this where the sensitivity and specificity were $100 \%$ and $100 \%$ compared to USG (kappa score 0.136 and $p$ value 0.004 ) which indicates a slight agreement between the US examination technique and operative finding with lower sensitivity where the calculated sensitivity in this trial was $31.5 \%$.

\section{Discussion}

The incidence of gallbladder perforation in acute cholecystitis has been reported to range from 2 to $18 \%$, and in between calculus and acalculous cholecystitis, the overall incidence of gallbladder perforation due to acalculous cholecystitis is higher (Fig. 1), reaching approximately 10 to $20 \%$ [5]. It is a rare but life-threatening event with mortality rates reaching 15\% [6]. The incidence of GBP in acute cholecystitis is 10\% [7]. Our study included with mean age 60 years, $57.8 \%$ were either known to be diabetic, and this agrees with Morris et al. that found it common in diabetic and cardiac patients and elderly patients are especially susceptible to GBP [1]. Acute uncomplicated cholecystitis is more common in females, but GBP is more common in males [8]. However, in this study, a higher incidence of GBP was observed in females (males to females $=8: 11$ ). In our study, the main complaint is severe abdominal pain associated with nausea, vomiting, and fever. Fourteen patients (73.6\%) had type 2 perforation (subacute, localized), only five had type 1 (acute, generalized peritonitis) perforation and this agrees with Derici et al. [9], and no patients type 3 perforation in our study. Gunasekaran et al. [10] had found that fundus is the most distal part with regards to the blood supply and therefore this makes it the most common site for perforation. This was also observed in our study with the most common site of perforation being the fundus. Ultrasonography is the main radiological examination done in most of the cases, but the findings are nonspecific and mimic those seen in acute uncomplicated cholecystitis such as distended GB (Fig. 2) (largest diameter $>3.5-4.0 \mathrm{~cm})$, thick $\mathrm{GB}$ wall $(>3 \mathrm{~mm})$, pericholecystic collection (Fig. 3), GB stones, and biliary dilatation. Distended GB with wall edema may be the earliest signs of impending perforation. Hole sign (a defect in the gallbladder wall) is the most specific finding [11]. Singal et al. [12] showed that the earliest signs of impending gall bladder perforation detectable on sonography may be distended gall bladder and edema of its walls along with liver abscess, which raise the suspicion of intrahepatic perforation. In our study, US examination was done for all patients and showed all previously described finding of inflammation detected as well as the
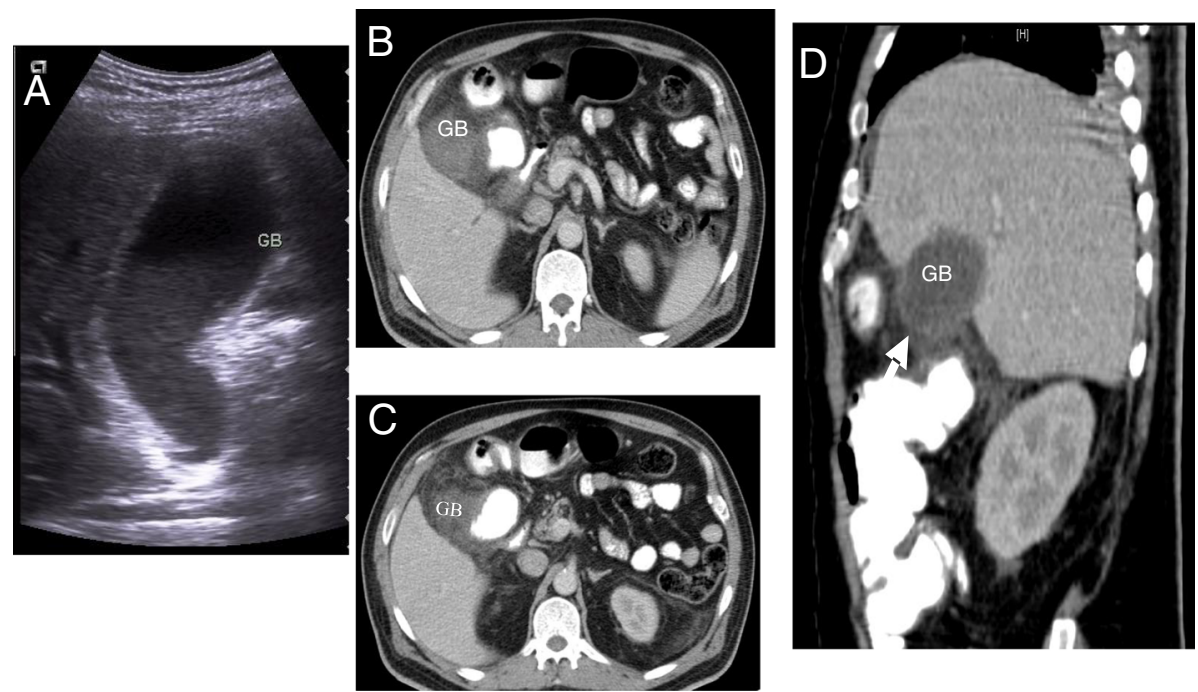

Fig. 2 56-year-old male has DM, HTN, and IHD presented with acute abdominal pain especially over RUQ associated with spikes of fever. a Admission US shows relative GB distension with biliary mud (bile-mud level). There were no stones or pericholecystic fluid. The patient did not improve on conservative treatment and pain was increasing. $40 \mathrm{~h}$ later, CT scan done, axial (b, c) and 2D sagittal reformat (d) shows lack of enhancement of GB wall, pericholecystic fluid collection, and inflammatory changes in juxtaposed hepatic flexure of colon. GB wall was not clearly identified at the fundus (arrow in $\mathbf{d}$ ). Laparoscopic cholecystectomy revealed a gangrenous GB filled with pus (acute non-calcular empyema and gangrenous GB) 
detected gall stones; however, the wall defect could not be detected except in two cases (Figs. 3 and 4). CT is the most sensitive examination to diagnose GBP [13]. The CT finding was classified into changes related to the GB, pericholecystic changes, and findings in other organs. GB changes include wall thickening, enhancement (except lack of enhancement of GB wall in gangrenous GB (Fig. 2)), wall defect (Figs. 1, 2, 4, and 5), intramural collection, intramural air, presence of GB stones (Fig. 6), biliary stones, and intraluminal gas. Pericholecystic changes include stranding of surrounding fat, fluid collection (Figs. 1, 2, 4, 5, and 6), biloma formation, and the presence of extra-luminal stones. Findings in other organs are such as pericholecystic hepatic enhancement (Fig. 5), hepatic abscess, portal vein thrombosis, thickening of adjacent intestinal loops wall (Fig. 2), pneumoperitoneum, ascites, and Mirizzi syndrome [11]. The GBP radiological finding can be divided into direct and indirect findings: the detection of either stone outside the gallbladder or a ruptured GB wall is a direct sign
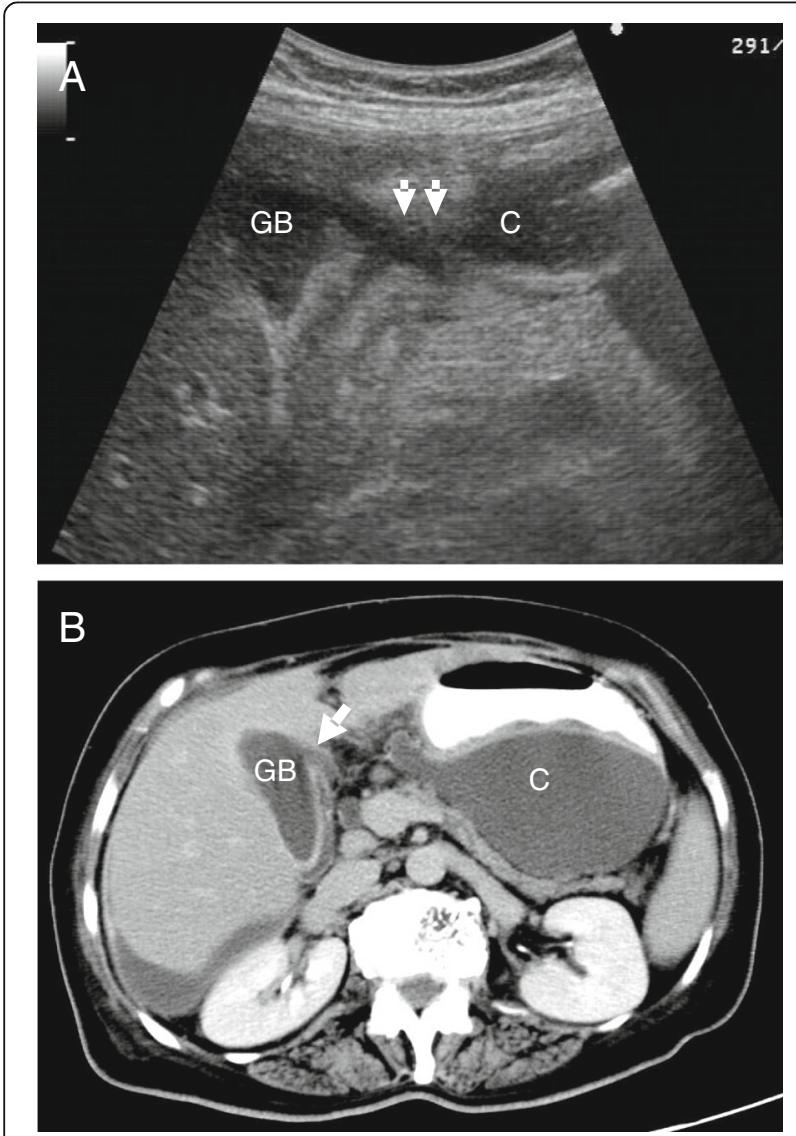

Fig. 3 A 53-year-old female presented with acute abdominal pain more in left upper quadrant. US (a) shows irregular GB outline with focal interruption and biliary mud. It was communicating (arrows) with collection in lesser sac (C). No stones. Axial CECT scan (b) shows focal defect in GB wall (arrow). GB rupture was confirmed during surgery

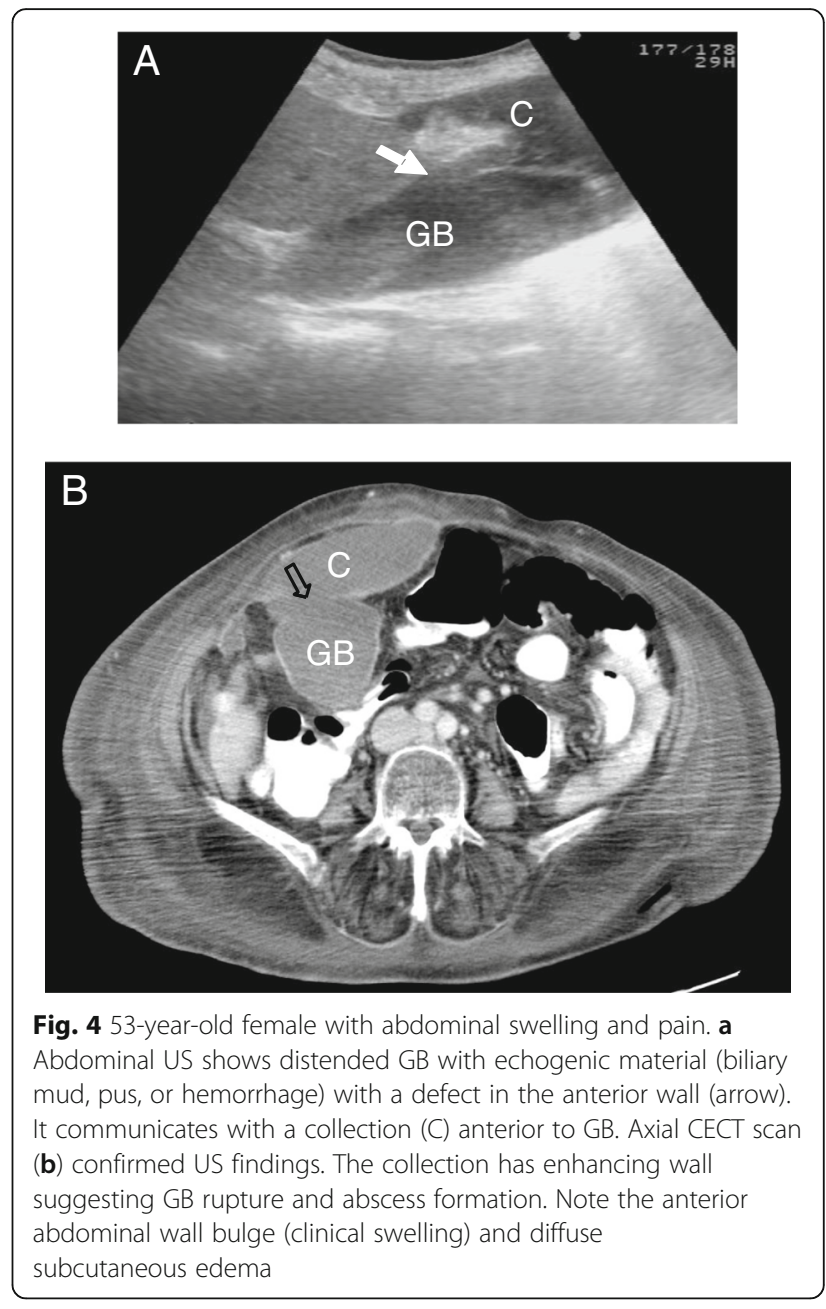

according to Kochar et al. [14]. Indirect signs include the presence of a collection outside the gallbladder and the presence of gallstones together with thick wall GB [11]. In our study, reviewing the CT findings of all patients, the most important finding was the detection of wall defect, either single or multiple, and its site the fundus, body, or neck. In the 19 patients in whom a perforation was identified at CT, $16(84.2 \%)$ were solitary. Multiple perforations were identified in only three cases (15.7\%) and this agrees with Chiapponi et al. [15]. Considering the complication, in our present study, all patients had free intraperitoneal free fluid, 17 patients had a pericholecystic collection, 10 patients had inflammatory changes in hepatic flexure of the colon, and 9 patients had pericholecystic hepatic enhancement and this agrees with Parekh et al. [16]. In our study, CT had no negative results compared to USG (13 out of $19=$ $68.4 \%)$. CT could correctly diagnose all cases of types I and II GBP and this agrees with O'Connor et al. [17]. In our study, we can see that there was a higher percentage of agreement between $\mathrm{CT}$ and operative findings with 


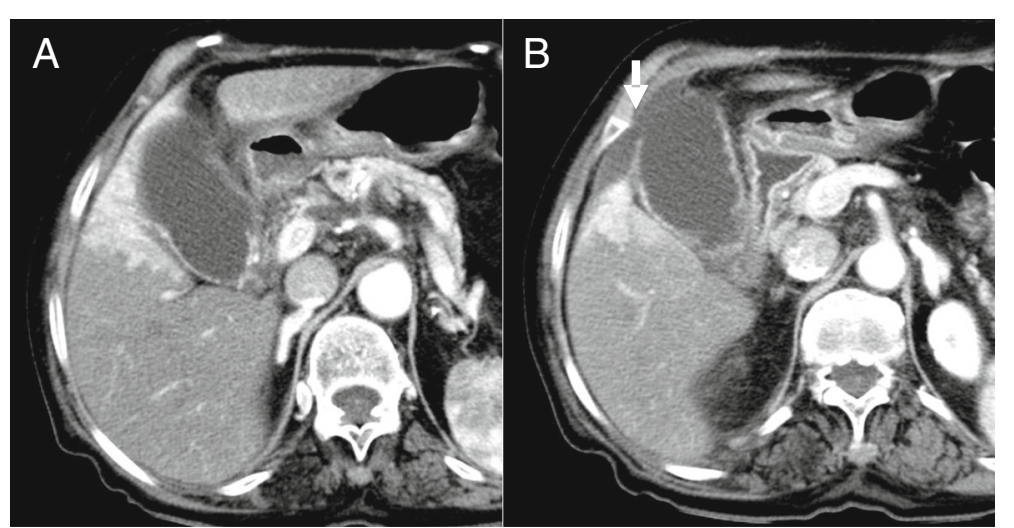

Fig. 5 A 60-year-old diabetic female with acute abdominal pain. Axial CECT (a, b) shows distended GB with a defect in the right anterior wall. It communicates with a collection anterior to the liver. Adjacent liver parenchyma shows reactive arterial enhancement. GB was perforated with gangrenous changes at the region of wall defect

highest sensitivity and specificity of CT examination technique in this where the sensitivity and specificity were $100 \%$ and $100 \%$ compared to USG which indicates a slight agreement between the US examination technique and operative finding with lower sensitivity where the calculated sensitivity in this trial was $31.5 \%$ and this agrees with Boruah et al. [18].

\section{Conclusions}

GBP is a rare but very serious condition and should be diagnosed and treated as soon as possible to decrease morbidity and mortality. The most accurate diagnostic tool is the CT, MSCT findings most specific and sensitive for the detection of GB perforation and its complications.
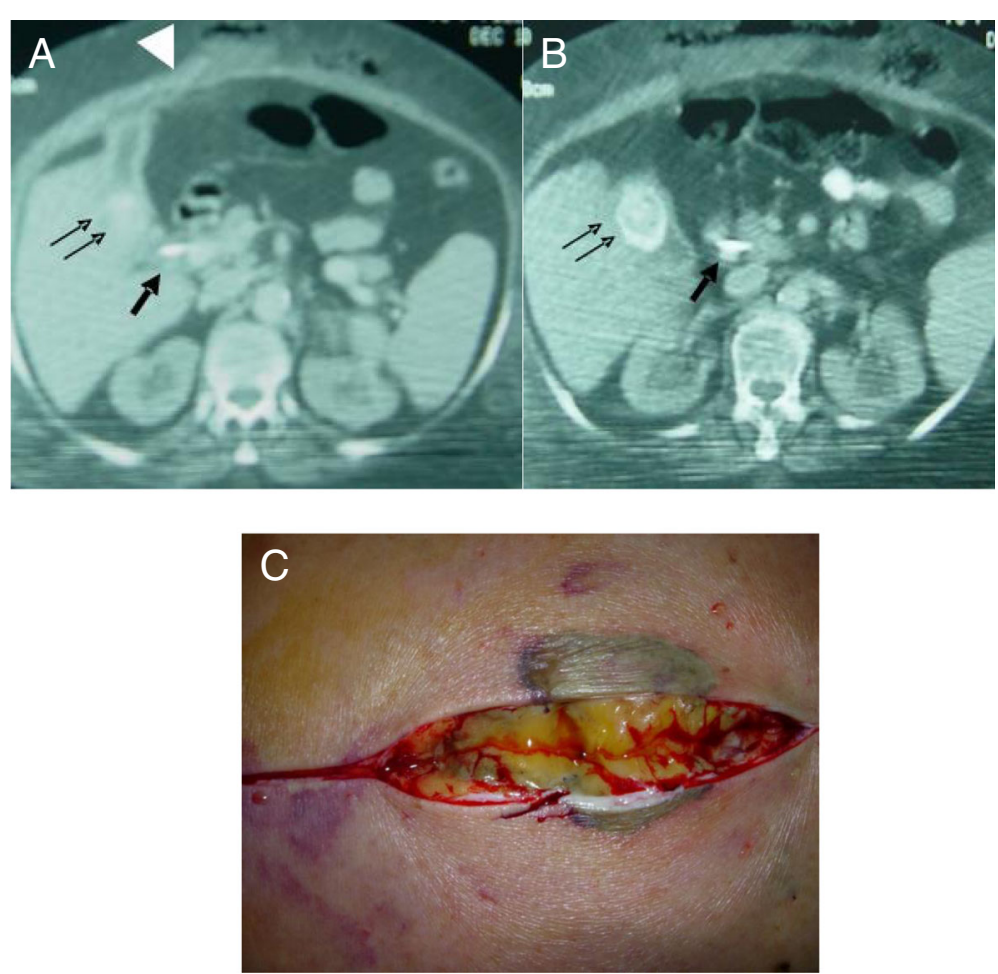

Fig. 6 GB perforation in a 70-year-old diabetic female presented with acute abdominal pain. US was relatively hampered by anterior abdominal wall gas and obesity. Axial CECT scan $(\mathbf{a}, \mathbf{b})$ shows contracted thick-walled GB with large stone (double arrows) at its neck. Stent is also noted (arrow). There are air and collection in the anterior abdominal wall with a track related to GB fundus (arrowhead). c Skin incision shows subcutaneous bile and bile-stained tissues. Note the inflammatory changes in the adjacent skin 


\section{Abbreviations}

CT: Computed tomography; GB: Gall bladder; GBP: Gallbladder perforation; MSCT: Multi-slice computed tomography

\section{Acknowledgements}

Not applicable

\section{Authors' contributions}

$\mathrm{MH}$ carried out the radiological studies, participated in the design of the study, gave idea and collected the patients' data, and performed the statistical analysis. AH participated in the sequence alignment and drafted the manuscript. AH participated in the acquisition of the data. $\mathrm{MH}$ participated in the sequence alignment. AH participated in the design of the study and performed the statistical analysis. $\mathrm{MH}$ conceived of the study, participated in its design and coordination, and helped to draft the manuscript. $\mathrm{MH}$ wrote the paper with revision. Both authors read and approved the final manuscript.

\section{Funding}

This study had no funding from any resource.

\section{Availability of data and materials}

The datasets used and/or analyzed during the current study are available

from the corresponding author on reasonable request.

\section{Ethics approval and consent to participate}

This study was approved by the Research Ethics Committee of Alnoor Hospital in Saudi Arabia. All patients included in this study gave written informed consent to participate in this research. The committee's reference number is not available.

\section{Consent for publication}

All patients included in this research gave written informed consent to publish the data contained within this study.

\section{Competing interests}

The authors declare that they have no competing interests.

Received: 19 November 2019 Accepted: 29 December 2019

Published online: 07 January 2020

\section{References}

1. Morris BS, Balpande PR, Morani et al (2007) The CT appearances of gallbladder perforation. Br J Radiol 80(959):898-901

2. Derici H, Kara C, Bozdag AD et al (2006) Diagnosis and treatment of gallbladder perforation. World J Gastroenterol 12(48):7832-7836

3. Swapnil S, Ujjwal KP (2018) Spontaneous gall bladder perforation: a rare clinical entity, a diagnostic and surgical challenge. Surg Med Open Acc J 1(1):SMOAJ.000505.

4. Konno K, Ishida H, Sato M et al (2002) Gallbladder perforation: color Doppler findings. Abdom Imaging 27:47-50

5. Nandyala VNR, Pallam P, Chintakindi SB et al (2016) Gall bladder perforation - is it still a diagnostic dilemma: a retrospective study. Int Surg J 3:609-613

6. Sood BP, Kalra N, Gupta S et al (2002) Role of sonography in the diagnosis of gallbladder perforation. J Clin Ultrasound 30:270-274

7. Indar AA, Beckingham IJ (2002) Acute cholecystitis. BMJ 325(7365):639-643

8. Chowksey SR, Baghel H, Sharma P et al (2014) Diagnosis of gallbladder perforation-a puzzle! Indian J Surg 76(3):247-250

9. Derici H, Kara C, Bozdag AD et al (2006) Diagnosis and treatment of gall bladder perforation. World J Gastroenterol 12:7832-7836

10. Gunasekaran G, Naik D, Gupta A et al (2015) Gallbladder perforation: a single center experience of 32 cases. Korean J Hepatobiliary Pancreat Surg 19(1):6-10

11. Sheoran SK, Sahai RN, Indora J et al (2016) Spontaneous perforation of gallbladder: case report. Gastroenterology Res 9(2-3):61-63

12. Singal R, Mittal A, Gupta S et al (2011) Management of gall bladder perforation evaluation on ultrasonography: report of six rare cases with review of literature. J Med Life 4(4):364-371

13. Tsai MJ, Chen JD, Tiu CM et al (2009) Can acute cholecystitis with gallbladder perforation be detected preoperatively by computed tomography in ED? Correlation with clinical data and computed tomography features. Am J Emerg Med 27(5):574-581

14. Kochar K, Vallance K, Mathew $G$ et al (2008) Intrahepatic perforation of the gall bladder presenting as liver abscess: case report, review of literature and Niemeier's classification. Eur J Gastroenterol Hepatol (3):240-244

15. Chiapponi, C, Wirth S \& Siebeck M. (2010) Acute gall bladder perforation with gallstones spillage in a cirrhotic patient. World J Emerg Surg 5(1):11

16. Parekh S, Andrawes S, Giordano C et al (2018) Acute perforated acalculous cholecystitis. Appl Radiol 47(2):20-23

17. O'Connor OJ, Maher MM (2011) Imaging of cholecystitis. AJR 196:367-374

18. Boruah DK, Sanyal S, Sharma BK et al (2016) Comparative evaluation of ultrasonography and cross-sectional imaging in determining gall bladder perforation in accordance to Niemeier's classification. J Clin Diagn Res 10(8): $15-18$

\section{Publisher's Note}

Springer Nature remains neutral with regard to jurisdictional claims in published maps and institutional affiliations.

\section{Submit your manuscript to a SpringerOpen ${ }^{\circ}$ journal and benefit from:}

- Convenient online submission

- Rigorous peer review

- Open access: articles freely available online

- High visibility within the field

- Retaining the copyright to your article

Submit your next manuscript at $\boldsymbol{\nabla}$ springeropen.com 